\title{
1942 - Brasil corta relações diplomáticas e declara Guerra a Alemanha. Como isto aconteceu?
}

\section{2 - Brazil breaks diplomatic relations and declares war on Germany. How did it happen?}

\author{
Andrea Helena Petry Rahmeier ${ }^{1}$
}

Resumo: $O$ presente artigo aborda questões relacionadas a conjuntura do corte das relações diplomáticas entre Brasil e Alemanha em janeiro de 1942 até a declaração brasileira de guerra em agosto do mesmo ano. Ao trabalhar com este tema utilizou-se a documentação militar e diplomática alemã. Esse conjunto de documentos apresenta a conjuntura e o contexto das ações e reações, principalmente as que ocorreram no oceano.

Palavras-chave: II Guerra Mundial, diplomacia, navios brasileiros.

\begin{abstract}
The present study addresses issues from the conjuncture regarding the rupture of diplomatic relations between Brazil and Germany on January, 1942 until the Brazilian declaration of war in August of that same year. This theme was researched based on German diplomatic and military documentation. This set of documents presents the conjuncture and the context of the actions and reactions, mainly the ones that took place in the ocean
\end{abstract}

Keywords: World War II, diplomacy, Brazilian ships.

As relações entre Brasil e Alemanha, no período da década de 1930 a 1942, foram caracterizadas por descontinuidades, pois foram guiadas pelas circunstâncias. Neste período não existe uma diretriz explícita de como deveriam ser as ações diplomáticas entre estes dois países. Este texto é parte da tese de doutorado defendida em março de 2009, intitulada "Relações diplomáticas e militares entre a Alemanha e o Brasil: da proximidade ao rompimento (1937-1942)".

A documentação brasileira sobre este tema foi fonte de pesquisa de alguns historiadores, entre eles, Ricardo Seitenfus, Gerson Moura e Wagner Alves. Todavia, a proposta deste texto é analisar como o governo alemão percebeu estes acontecimentos, para isto, a documentação utilizada advém

\footnotetext{
1 Doutora em História pela Pontifícia Universidade Católica do Rio Grande do Sul PUC/RS, professora do curso de História da FACCAT - Faculdades Integradas Taquara. Email: andrearahmeier@ faccat.br.
} 
do Ministério das Relações Exteriores da Alemanha, (Auswärtiges Amt ${ }^{2}$, doravante AA), com seus documentos diplomáticos que estão à disposição no seu arquivo político (Politischen Archiv des Auswärtiges Amts, doravante PAAA); e do Arquivo Nacional Alemão, sobre as questões militares (Bundesarchiv - Abteilung Militärarchiv, doravante BA $\mathrm{MA}^{3}$ ). Neste sentido, o presente artigo baseou-se em documentos dos arquivos alemães para analisar as relações brasileiras com este país. O estudo dessa documentação teve o cuidado de tentar averiguar por quem e para quem foram escritos os documentos. Para isto utilizou-se como metodologia o cruzamento fotocopiado e fotografado da correspondência e de outros documentos arquivados em cada um dos ministérios alemães e dentro de cada órgão governamental sobre o Brasil, gerando uma análise sinótica da documentação diplomática e militar alemã. Isso proporcionou a análise do conjunto das informações elaboradas pelos diplomatas e militares alemães sobre o Brasil, dando condições de entender melhor a linha de raciocínio e não apenas conhecer algumas afirmações feitas em documentos específicos, sem uma contextualização de cada um dos documentos analisados.

A metodologia adotada teve por finalidade responder ao problema principal: como o governo alemão percebeu e reagiu ao contexto do corte das relações diplomáticas brasileiras e suas ações durante o ano de 1942.

\section{Síntese da conjuntura diplomática entre Brasil e Alemanha}

Até fins de 1937, houve certa proximidade política entre os governos de Getúlio Vargas e de Adolf Hitler; todavia, havia entendimentos divergentes sobre a concepção de nacionalidade. Isso porque o conceito de nação alemã remetia a um passado em comum e o brasileiro tentava projetar um futuro em comum. Essas divergências tiveram pouca importância no período em que ambos os países estavam estruturando sua política interna e externa, isto é, até fins de 1937. Todavia, a partir de 1938, com as novas leis nacionalizadoras do governo brasileiro, ocorreu o choque entre as posturas

\footnotetext{
${ }^{2}$ É interessante observar que esse arquivo, até 1999, estava em Bonn. Naquele ano, iniciouse a transferência do arquivo diplomático para Berlim. Isso ocorreu porque, desde 1990, houve o processo de unificação entre a Alemanha Ocidental e a Oriental. Outro dado relevante é a atualização/alteração na nomenclatura dos documentos. Sendo assim, se comparadas citações de obras publicadas antes de 1990 com as utilizadas nesse artigo, existem diferenças.

${ }^{3}$ A primeira instituição localiza-se em Berlim e a última, na cidade de Freiburg. A pesquisa nos arquivos foi realizada no segundo semestre de 2006.
} 
assumidas em relação ao nacionalismo. Ainda que essas concepções diferentes constituíssem fontes de tensões, continuava a haver razões de aproximação.

$\mathrm{O}$ grande interesse alemão nas relações com o Brasil era $\mathrm{o}$ comércio, porque aquele país carecia de matérias-primas diversificadas e produtos agrícolas, e também necessitava de um mercado consumidor para seus inúmeros produtos industrializados. Já o Brasil possuía uma diversidade de matérias-primas e também o desejo de consumir muitos produtos manufaturados. Dessa situação, ambos os países usufruíram de inúmeras vantagens através do comércio de compensação, o qual possibilitou atender às intenções comerciais dos dois lados. As relações comerciais estiveram em franco crescimento até o início da guerra na Europa, setembro de 1941. O comércio foi o assunto-chave nas relações diplomáticas entre Brasil e Alemanha, tanto é que torna-se relevante informar que o mesmo, no decorrer do ano de 1938, não foi atingido pelos problemas políticos gerados pela ruptura parcial das relações políticas e diplomáticas. Os dados extraídos da documentação alemã analisada no desenrolar da tese e a historiografia brasileira ${ }^{4}$ sobre $o$ assunto demonstraram que houve um crescimento da demanda tanto na importação quanto na exportação entre os dois países, durante a retida dos respectivos embaixadores 5 .

Outro fator que propiciava proximidade entre os países em questão era a possibilidade do Brasil comprar material bélico. A retomada da produção de armamentos pela Alemanha e o comércio de compensação permitiu às forças armadas brasileiras assinar contratos, em março de $1938 \mathrm{e}$ julho de 1939, para a aquisição de armas junto a um conjunto de empresas alemãs, lideradas pela Krupp. Essas tratativas aproximaram os militares dos dois países, pois ambos sairiam ganhando. Em síntese, os militares brasileiros estavam desejosos em aparelhar o exército e o governo alemão queria estreitar ainda mais as relações comerciais com o Brasil, através do comércio de compensação. ${ }^{6}$

\footnotetext{
${ }^{4}$ Principalmente na obra de:

SEITENFUS, Ricardo Antônio Silva. O Brasil de Getúlio Vargas e a formação dos blocos, 1930-1942: o processo de envolvimento brasileiro na II Guerra Mundial. São Paulo: Ed. Nacional; (Brasília): INL, Fundação Nacional Pró-Memória, 1985.

${ }^{5}$ Para maiores detalhes ver capítulo três da tese:

${ }^{6}$ Este assunto é desenvolvido nos três primeiros capítulos da tese, onde pode ser encontrado informações detalhadas sobre cada um deles. Este assunto por si só daria um artigo.
} 
Com o início da guerra, em setembro de 1939, conforme a documentação diplomática alemã, as relações entre a Alemanha e a América passaram a ter uma diretriz emanada do Ministério das Relações Exteriores da Alemanha, a qual determinava que os diplomatas alemães da América deveriam fazer de tudo possível para manter a neutralidade nos países que atuavam. Entre setembro de 1939 e junho de 1941, o bloqueio naval executado pelos ingleses dificultou e, algumas vezes, até impossibilitou as relações comerciais entre Alemanha e Brasil. Entretanto, ainda sobreviveu o predomínio das relações diplomáticas entre ambos. ${ }^{7}$

O corte das relações diplomáticas entre Brasil e Alemanha, no dia 28 de janeiro de 1942, ao final da III Reunião dos Chanceleres, ocorrida no Rio de Janeiro, aparentemente encerrou as indefinições brasileiras surgidas após a declaração de guerra estadunidense aos alemães. Antes dessa data, ocorreram diversas tratativas, diretas e indiretas para que a mesma não se efetuasse, todavia, sem sucesso ${ }^{8}$. Mesmo assim, logo após esse acontecimento, a diplomacia alemã ainda tinha esperança de que, em algum momento, poderia haver, por parte do Brasil, um retorno à condição de neutralidade, pois ainda não estava declarada a guerra, somente havia uma aproximação maior entre Brasil e EUA.

\section{2 - Atuação marítima alemã no Atlântico}

Durante a II Guerra Mundial, o mar tornou-se um dos principais campos de batalha. O auge da ação marítima alemã foi o ano de 1942. Neste mesmo ano, houve uma ampliação do espaço da guerra marítima, momento que passou a ser incluídas ações de guerra nos mares próximos ao continente americano. Em fins de 1941, depois do ataque japonês a Pearl Harbor, a situação se alterou. Momento em que os EUA declararam Guerra aos países do Eixo e que, posteriormente, o México e oito países da América Central ou cortaram relações diplomáticas ou também declararam guerra aos países do Eixo (Cuba, Nicarágua, Costa Rica, Guatemala, Honduras, San Salvador, Haiti e Panamá). Em outras palavras, a América Central e o México não hesitaram em referendar as decisões da Conferência

\footnotetext{
7 Em função do tamanho deste artigo para maiores detalhes ver: RAHMEIER, Andrea. Relações diplomáticas e militares entre a Alemanha e o Brasil: da proximidade ao rompimento (1937-1942). Porto Alegre, 2009, 390 p. Tese de doutorado. Pontífice Universidade Católica/RS, principalmente capítulo 4 e 5 .

${ }^{8}$ Em função do tamanho deste artigo para maiores detalhes de todo este contexto ver: RAHMEIER, Idem,.
} 
de Havana (1940), com isto, também demonstraram apoio aos Estados Unidos. Fato diverso ocorreu na América do Sul, pois somente dois países (Colômbia e Venezuela) alteraram a situação diplomática com a Alemanha antes da Conferência do Rio de Janeiro. Nos primeiros meses de 1942, as ações eram executadas nos mares próximos da região norte e central da América. Todavia, como após a Conferência do Rio de Janeiro somente Chile e Argentina não cortaram relações diplomáticas ou declararam guerra aos países do Eixo, as ações, com o passar dos meses, se direcionavam cada vez mais ao sul.

Neste novo contexto de guerra naval, os países americanos não estavam preparados de imediato para enfrentar ataques a seus navios cargueiros e nem a possíveis ações de defesa do território americano. Contudo, a partir do segundo semestre deste ano, a situação se alterou e os países aliados iniciaram a implementação de algumas formas de defesa para a navegação marítima americana, que foi muito utilizada pelo Brasil ${ }^{9}$.

Na tentativa de compreender as ações alemãs próximas da costa do continente americano, usar-se-á quadros criados a partir de um relatório elaborado pelo Oberkommando der Kriegsmarine (Comando Supremo da Guerra Marinha Alemã). O documento em questão foi produzido em 20 de janeiro de 1943 e tem por título: Feindliche Handelsschiffsverluste Von Kriegsbeginn bis zum 31.12.1942 (Perdas dos inimigos do começo da guerra até 31.12.1942). Importante lembrar que esse documento foi produzido no auge da guerra e, pelo teor, pretende demonstrar as ações e os respectivos sucessos dos submarinos alemães. Outro cuidado necessário ao analisar este documento é ter consciência que o mesmo informa os ataques, mas não quais foram as consequências destes para as devidas embarcações, pois as mesmas podem ter sofrido apenas avarias e não precisamente terem sido afundadas. É relevante analisar esta documentação, pois assim pode-se compreender as informações que circulavam dentro da marinha alemã sobre os navios dos países americanos. Não é demais reafirmar que, provavelmente, estes dados não são exatos ou até nem próximos aos reais, pois o documento analisado foi o produzido durante a guerra. Estes documentos possibilitam a percepção de que não tiveram intenções e nem condições de conferir dados, apenas lançavam as informações que eram repassadas pelos comandantes de submarinos e outras embarcações de

${ }^{9}$ Para maiores detalhes da estratégia de defesa adotada pelos navios brasileiros a partir de junho de 1942 ver a obra de: OLIVEIRA, Dennison de. Aliança Brasil-EUA: Nova História do Brasil na Segunda Guerra Mundial. Curitiba: Juruá, 2015 
guerra alemã. Os dados dos quadros a seguir foram extraídos da documentação militar alemã, porém, não estão na ordem de distribuição original, pois o documento tem mais de 20 páginas e por uma questão metodológica, optou-se em trabalhar somente com os dados do continente americano.

No continente americano, em 1942, o país com mais embarcações atingidas foi os Estados Unidos. Nos dados da marinha alemã, foram 583 embarcações, tanto de carga, quanto de tanque. Todavia, a documentação informa que foram 444 navios de carga, demonstrando que o principal objetivo dos submarinos era ataques direcionados para barrar a chegada de embarcações com suprimentos destinados ao consumo humano e para a indústria dos países inimigos. Isto é, era necessário fazer o bloqueio naval, prática adotada desde o início da guerra no continente europeu.

Um dos dados que consta neste material, e que surpreende, é o Chile e a Argentina estarem neste quadro de relatos de perdas dos inimigos, pois neste momento ambos os países eram neutros e vistos pelos Aliados como parceiros da Alemanha. Contudo, é necessário relativizar que este documento era interno do Comando Supremo da Guerra Marinha Alemã e pela pesquisa percebeu-se que os dados específicos desse documento não circularam dentro do Ministério das Relações Exteriores da Alemanha.

Nesse mesmo relatório, consta que, em 1942, os submarinos alemães atingiram embarcações que totalizam 10.972.216 toneladas. Entretanto, entre 1939 e 1942 foram atingidas 24.748.401 toneladas. Isto é, em 1942, pela documentação alemã, os submarinos atingiram quase a metade das embarcações executados nos três anos anteriores (1939 a 1941), referendando que até 1942 a guerra marítima estava em franco crescimento. Como esse relatório não abrange o ano de 1943, não se pode informar dados que demonstrem que este foi o auge das ações de guerra marítima alemã, pois o referido documento não tem dados do declínio desta ação.

$\mathrm{O}$ documento em questão apresenta dois tipos de dados. $\mathrm{O}$ primeiro com informações dos ataques efetuados às embarcações em 1942 (Quadro I) e outro com os dados desde o início da guerra a 1942 (Quadro II). Optou-se para este momento apresentar as duas sínteses no que se refere aos países americanos.

Quadro I - Perdas dos inimigos no ano de 1942

\begin{tabular}{|l|r|r|r|r|r|r|}
\hline \multirow{2}{*}{ Nacionalidade } & \multicolumn{2}{|c|}{ Navio de carga } & \multicolumn{2}{c|}{ Navio tanque } & \multicolumn{2}{c|}{ Total } \\
\cline { 2 - 7 } & \multicolumn{1}{|c|}{$A n z}$. & \multicolumn{1}{c|}{$B R T$} & $A n z$. & \multicolumn{1}{c|}{$B R T$} & \multicolumn{1}{c|}{$A n z}$. & \multicolumn{1}{c|}{ BRT } \\
\hline EUA & 444 & 2.009 .062 & 140 & 945.302 & 583 & 2.954 .364 \\
\hline Panamá & 60 & 232.548 & 32 & 289.525 & 92 & 522.073 \\
\hline
\end{tabular}




\begin{tabular}{|l|r|r|r|r|r|r|}
\hline Brasil & 25 & 96.767 & 2 & 6.816 & 27 & 103.583 \\
\hline Honduras & 5 & 10.756 & - & - & 5 & 10.756 \\
\hline México & 4 & 28.135 & 1 & 6.511 & 5 & 34.646 \\
\hline Argentina & 4 & 13.444 & - & - & 4 & 13.444 \\
\hline Cuba & 3 & 3.410 & - & - & 3 & 3.410 \\
\hline Chile & 2 & 3.054 & - & - & 2 & 3.054 \\
\hline Colômbia & 2 & 291 & - & - & 2 & 291 \\
\hline República & 2 & 3.641 & - & - & 2 & 3.641 \\
Dominicana & & & & & & \\
\hline Nicarágua & 2 & 2.653 & - & - & 2 & 2.653 \\
\hline Uruguai & 2 & 11.070 & - & - & 2 & 11.070 \\
\hline Venezuela & 1 & 150 & 1 & 2.651 & 2 & 2.801 \\
\hline
\end{tabular}

Fonte: Documentação do departamento Akten der Abteilungen und Amtsgruppen, pasta Gruppe Fremde Handelsschiffart, com o código de arquivamento: RM/7 2790 do BA MA.

Ao analisar os dados específicos dos Estados Unidos desde 1939, observa-se que após a sua declaração de guerra foram atingidas 583 embarcações (Quadro I) e que antes do envolvimento direto na guerra, num período de dois anos e alguns meses (setembro de 1939 a dezembro de 1941) foram atingidos somente 86 navios (Quadro II). Nos demais territórios da América, observa-se a mesma situação dos EUA, pois o ataque dos submarinos aos navios dos países americanos também tiveram como o auge das ações o ano 1942. Todavia, alguns países americanos só passaram a ter suas embarcações atacadas em 1942 como, por exemplo, Colômbia, República Dominicana, Cuba e Uruguai. Os países que não constam nesta lista (por exemplo, na América do Sul faltam Peru, Paraguai e Equador), conforme o relatório em questão, não foram atingidos pelos alemães até 1942.

Quadro II - Perdas dos inimigos do começo da guerra até 31.12.1942

\begin{tabular}{|l|r|r|r|r|r|r|}
\hline \multirow{2}{*}{$\begin{array}{c}\text { Nacionalidad } \\
\text { e }\end{array}$} & \multicolumn{2}{|c|}{ Navio de carga } & \multicolumn{2}{c|}{ Navio tanque } & \multicolumn{2}{c|}{ Total } \\
\cline { 2 - 7 } & Anz. & \multicolumn{1}{c|}{ BRT } & Anz. & \multicolumn{1}{c|}{ BRT } & Anz. & \multicolumn{1}{c|}{ BRT } \\
\hline EUA & 522 & 2.331 .748 & 147 & 1.019 .295 & 669 & 3.351 .043 \\
\hline Panamá & 77 & 276.505 & 39 & 343.089 & 116 & 619.594 \\
\hline Brasil & 29 & 107.161 & 3 & 13.886 & 32 & 121.047 \\
\hline México & 8 & 33.727 & 1 & 6.511 & 9 & 40.238 \\
\hline Honduras & 6 & 13.740 & - & - & 6 & 13.740 \\
\hline Argentina & 5 & 16.069 & - & - & 5 & 16.069 \\
\hline Chile & 4 & 4.027 & - & - & 4 & 4.027 \\
\hline Venezuela & 1 & 150 & 3 & 14.657 & 4 & 14.807 \\
\hline
\end{tabular}




\begin{tabular}{|l|r|r|r|r|r|r|}
\hline Cuba & 3 & 3.410 & - & - & 3 & 3.410 \\
\hline Nicarágua & 3 & 3.299 & - & - & 3 & 3.299 \\
\hline Colômbia & 2 & 291 & - & - & 2 & 291 \\
\hline $\begin{array}{l}\text { República } \\
\text { Dominicana }\end{array}$ & 2 & 3.641 & - & - & 2 & 3.641 \\
\hline Uruguai & 2 & 11.070 & - & - & 2 & 11.070 \\
\hline
\end{tabular}

Fonte: Documentação do departamento Akten der Abteilungen und Amtsgruppen, pasta Gruppe Fremde Handelsschiffart, com o código de arquivamento: RM/7 2790 do BA MA. ${ }^{10}$

Brasil, em número de perda de embarcações, comparativamente com os demais países da América, só perdeu para EUA e Panamá, isto é, estava em terceiro lugar no número de navios atacados pelos alemães. Uma outra informação deste documento, que chama a atenção, é a de que antes de 1942, foram atacados 5 navios brasileiros. ${ }^{11}$ Os dados oficiais do governo brasileiro, para o período anterior a 1942, confirmam apenas o ataque, em março de 1941, do navio Taubaté. Talvez houvesse, por parte dos alemães, a ampliação dos números ou outros afundamentos que o governo brasileiro considerou acidentes, mas que, na verdade, haviam sido atacados por submarinos alemães. Por isto, no que se refere aos dados brasileiros, também é necessário relativizar os números.

Os dados da marinha alemã são diferentes e superiores aos apresentados pela maioria dos historiadores de diversos países, fato que possibilita pelo menos duas hipóteses: uma, que essa diferença tenha ocorrido porque alguns ataques provocaram pequenas avarias que nem foram computadas pelos aliados; outra, que os números alemães foram ampliados para levantar a autoestima da sua marinha. Ou ainda, que existiu uma desorganização nos dados alemães que levou a estas discrepâncias.

\section{Ataques alemães aos navios brasileiros}

Em 1942, com a declaração de guerra da Alemanha aos Estados Unidos e o consequente corte ou declaração de guerra da maioria dos países americanos, o Atlântico Norte tornou-se uma nova área de combate. Em fevereiro, foram afundadas 71 embarcações (384 mil toneladas), sendo que,

\footnotetext{
${ }^{10} \mathrm{O}$ documento trata de diversos países, mas para fins de análise só foram explicitados os dados dos navios dos países do continente americano.

${ }^{11}$ Nos registros alemães, não consta o nome dos navios, apenas a quantidade e o tipo de embarcação, carga ou tanque.
} 
destas, apenas duas não estavam na zona continental americana. Entre estes afundados no Atlântico Norte, durante o mês de fevereiro, estavam os navios brasileiros: Buarque e Olinda. ${ }^{12}$

O governo brasileiro tentou, pela via diplomática portuguesa ${ }^{13}$,junto ao governo alemão, obter informações daquilo que estava ocorrendo com seus navios. Com esse fim, em 26 de fevereiro de 1942, o diplomata português Graf Tovar, representante dos interesses brasileiros em Berlim, teve uma audiência no AA. Nesse momento, foram abordados, de forma não oficial, os ataques aos navios brasileiros Olinda e Buarque. Todavia, não se obteve informações oficiais da diplomacia alemã. ${ }^{14}$

A marinha alemã estava executando ataques desordenados a todos os navios que transportavam matéria-prima para os EUA. Outro fato que se percebe, nos primeiros meses de 1942, é que os oficiais alemães responsáveis pelos registros não estavam preparados para incorporar os dados de uma nova frente de batalha, pois as informações não tinham a mesma sequência lógica que ficou explícita a partir de abril daquele ano. $\mathrm{Na}$ sequência do texto, serão apresentados quadros (III, IV, V, VI) dos navios brasileiros torpedeados de janeiro a agosto de 1942. Estes quadros foram criados através de dados retirados dos registros dos submarinos alemães (Kriegstagebuch des Befehlshaber, Führer der Unterseeboote/ Befehlshaber der Unterseeboote, 1939 a 1942). ${ }^{15}$ Sabe-se que o peso das embarcações em alguns casos não estão corretos, mas, no sentido de ser fiel ao documento

\footnotetext{
12 Para maiores detalhes sobre o afundamento dos navios brasileiros:

BRASIL. Ministério das Relações Exteriores. O Brasil e a segunda guerra mundial. - Rio de Janeiro: Imprensa Nacional, 1944. 2 v.

GAMA, Arthur Oscar Saldanha da. A marinha do Brasil na segunda guerra mundial. Rio de Janeiro: Capemi, 1982.

SEITENFUS, Ricardo Antônio Silva. O Brasil de Getúlio Vargas e a formação dos blocos, 1930-1942: o processo de envolvimento brasileiro na II Guerra Mundial. São Paulo: Ed. Nacional; (Brasília): INL, Fundação Nacional Pró-Memória, 1985.

Também existe um trabalho que faz uma abordagem mais jornalística sobre o tema:

SANDER, Roberto. O Brasil na mira de Hitler: A história do afundamento de navios brasileiros pelos nazistas. Rio de Janeiro: Objetiva, 2007.

13 Com a ruptura nas relações diplomáticas, foi necessário procurar governos que representassem os interesses alemães e brasileiros. Portugal passou a representar o Brasil na Alemanha e a Espanha representou a Alemanha no Brasil.

${ }^{14}$ Registro $\mathrm{n}^{\circ} 151$ da audiência, entre diplomata português e Woermann, de 26 de fevereiro de 1942, arquivado dentro do Büro des Staatssekretärs, na pasta Brasilien (4.1938 a 2.1942, Band 1), com o código de arquivamento: R-29548 do PAAA.

15 Dados retirados do Kriegstagebuch des Befehlshaber, Führer der Unterseebootel Befehlshaber der Unterseeboote (1939 a 1942), com o código de arquivamento: RM 87 do BA MA.
} 
pesquisado, não foram alterados. Outra constatação, observada nos dados deste relatório, é que em alguns momentos as informações eram imprecisas, pois inicialmente não tinha o nome do navio atacado. Por exemplo, o caso da embarcação Cairú, que no documento apresenta dados de pesagem e de afundamento digitados e depois tem o registro a punho do nome Cairú. Ou seja, as informações eram feitas, mas em muitos momentos eram incompletas. Interessante informar que os navios atingidos pelos submarinos italianos também fazem parte dos registros alemães, como é o caso da embarcação Comandante Lira que foi atingida pelo submarino italiano Barbarigo.

Quadro III - Navios brasileiros atacados em fevereiro e março de 1942
\begin{tabular}{|c|c|c|c|c|}
\hline $\begin{array}{c}\text { Sequência de } \\
\text { afundamentos }\end{array}$ & $\begin{array}{c}\text { Data do } \\
\text { ataque }\end{array}$ & $\begin{array}{c}\text { Nome do navio } \\
\text { atingido }\end{array}$ & $\begin{array}{c}\text { Submarino que } \\
\text { atacou }\end{array}$ & BRT \\
\hline 1. & $15 / 02 / 1942$ & Buarque & U-432 & 5.152 \\
\hline 2. & $18 / 02 / 1942$ & Olinda & U-432 & 4.053 \\
\hline 3. & $07 / 03 / 1942$ & Arabutan & U-155 & 7.874 \\
\hline 4. & $07 / 03 / 1942$ & Cairú & U-94 & 5.152 \\
\hline
\end{tabular}

O governo brasileiro, em março de 1942, reagiu ao torpedeamento de quatro de seus navios (Quadro III), através do decreto-lei no 4.166 (que se refere às indenizações por atos de agressão contra bens brasileiros) e houve a intensificado na prisão de cidadãos alemães. Isto só ocorreu a partir deste momento, porque foi em janeiro de 1942 que o governo brasileiro cortou relações diplomáticas com a Alemanha. Fato que significou que ambos os países não tinham relações mútuas, política ou juridicamente, através dos seus representantes autorizados. Então, a partir daquele momento, os cidadãos alemães que permaneceram no Brasil tinham que seguir as regras brasileiras e não tinham como recorrer aos seus representantes diplomáticos. No caso de cidadãos brasileiros na Alemanha ocorreu a mesma situação. Foi a prisão de cidadãos alemães que mais preocupou o Ministério das Relações Exteriores da Alemanha, tanto que foram executados dois movimentos. Primeiro, em maio, houve o contato com a Cruz Vermelha Internacional, para que esta averiguasse, junto ao governo brasileiro, a situação dos cidadãos daquele país. Segundo, em junho, o próprio Ribbentrop, ministro das Relações Exteriores da Alemanha desde 1937, assinou um comunicado para a diplomacia espanhola, que era a sua representação junto ao governo brasileiro, afirmando que, se o Brasil não mudasse sua atitude, seriam os cidadãos brasileiros, na Alemanha, que iriam sofrer as consequências. Entretanto, a própria diplomacia alemã sabia 
que essa ação não teria o efeito esperado, pois o número de cidadãos brasileiros naquele país foi considerado insuficiente para as ações terem a dimensão desejada, uma vez que, na Alemanha, havia 695 brasileiros, entre eles 502 descendentes de alemães, dos quais 88 estavam detidos. Na França, Holanda, Bélgica e Noruega, havia 70 brasileiros e destes, 30 estavam detidos. ${ }^{16}$ Provavelmente, as pessoas detidas eram os diplomatas brasileiros que estavam confinados em hotéis.

A partir de julho daquele ano, contudo, a situação dos cidadãos alemães presos no Brasil melhorou, fato que amenizou os ânimos da diplomacia. O repatriamento dos diplomatas alemães e brasileiros transcorreu com tranquilidade, pois foram atendidos os pedidos de ambos os lados. Prüfer, embaixador alemão no Rio de Janeiro de setembro de 1939 a janeiro de 1942, tentou retardar sua saída do Brasil porque acreditava que, desse modo, conseguiria ampliar o número de cidadãos alemães a serem repatriados e, também, poderia analisar a situação brasileira in loco, mandando informações para a Alemanha, através de Buenos Aires. Entretanto, em agosto, o governo brasileiro restringiu sua liberdade de ação. Esse fato fez com que Prüfer retornasse ao seu país no próximo navio, com cidadãos repatriados, o que ocorreu no mês de setembro de 1942.

As ações brasileiras para com os cidadãos alemães incomodavam a diplomacia alemã. Todavia, a colocação de canhões nos navios brasileiros, a partir de maio de 1942, irritou a marinha alemã. Tanto é que foi autorizado, na segunda quinzena de maio, o ataque aos navios sul-americanos armados que faziam o comércio com os Estados Unidos. Neste caso, foi explicitado que a exceção seriam as embarcações argentinas e chilenas. Essa situação ocasionou cinco novos afundamentos de navios brasileiros, entre maio e junho de 1942(Quadro IV). Deve-se lembrar que de fevereiro a abril, isto é, três meses, foram afundados quatro navios e de maio a junho, dois meses, foram outros cinco (Quadro III).

Quadro IV - Navios brasileiros atacados em maio e junho de 1942

\begin{tabular}{|c|c|c|c|c|}
\hline $\begin{array}{c}\text { Sequência de } \\
\text { afundamentos }\end{array}$ & $\begin{array}{c}\text { Data do } \\
\text { ataque }\end{array}$ & $\begin{array}{c}\text { Nome do navio } \\
\text { atingido }\end{array}$ & $\begin{array}{c}\text { Submarino que } \\
\text { atacou }\end{array}$ & BRT \\
\hline 5. & $01 / 05 / 1942$ & Paranaíba & U-162 & 6.692 \\
\hline 6. & $18 / 05 / 1942$ & Comandante Lira & Barbarigo & 5.052 \\
\hline 7. & $24 / 05 / 1942$ & Gonçalves Dias & U-502 & 4.996 \\
\hline 8. & $01 / 06 / 1942$ & Alegrete & U-156 & 5.970 \\
\hline
\end{tabular}

16 Diplogerma interno, R7330, de 14 de março de 1942, arquivado dentro do Kriegsrecht Fremde Zivilgefangene in Deutschland, na pasta Brasilien (1.1942 a 1944, Band 1), com o código de arquivamento: R-41406 do PAAA. 
A partir de maio de 1942, existe uma maior documentação sobre o Brasil nos arquivos militares alemães. Esta constatação e o teor existente nos documentos possibilita a afirmação de que houve uma maior participação dos militares alemães nos assuntos relacionados ao Brasil.

Em fins de maio, após o ataque ao navio Comandante Lira, a Força Aérea Brasileira divulgou na imprensa nacional que atacou submarinos eixistas, tendo atingido um. Esta notícia foi divulgada em jornais de diversos países, principalmente na América Latina, a partir de 28 de maio. ${ }^{17}$ Neste mesmo dia, a diplomacia e os militares alemães começam uma investigação interna para averiguar a veracidade das reportagens, tanto entre seus submarinos quanto nos italianos e japoneses. No início de junho, averiguou-se que, próximo à data da divulgação feita pela imprensa, nenhum submarino havia sido atingido dentro do território brasileiro. Porém, dois submarinos italianos foram atingidos longe do local informado, isto é, litoral brasileiro e, por coincidência, um dos atingidos foi o Barbarigo. Fato que teria ocorrido entre 15 e 22 de maio, ou seja, próximo dos dias em que o submarino torpedeou a embarcação brasileira Comandante Lira. Sendo assim, a notícia de que um avião brasileiro teria atingido um submarino proporcionou a certeza de que o Brasil pretendia executar atitudes de guerra, mesmo não a tendo declarado, situação que se tornou mais complexa a cada dia. Nos dias de hoje, através das divulgações de pesquisas atuais, como de Dennison de Oliveira, sabe-se que a Força Aérea Brasileira atingiu o submarino italiano Barbarigo, mas na documentação alemã esta informação não estava explícita.

As reportagens sobre as ações da aviação brasileira forneceram um subsídio a mais para o Brasil tornar-se pauta nas discussões dos militares alemães, tanto é, que iniciaram a averiguação da possibilidade e viabilidade de se atacar os portos brasileiros. Especificamente, no dia 30 de maio de 1942, foram elaborados, pela marinha alemã, dois documentos detalhando sobre as vantagens, desafios e dificuldades em um possível ataque aos portos brasileiros. Os documentos em questão iniciam considerando que o Brasil, provavelmente, declararia guerra à Alemanha. Um deles intitula-se Vortragsnotiz (apontamentos da audiência ou ata de uma apresentação) e é constituído de cinco páginas. Nele foram abordados: o comércio do Brasil com os Estados Unidos, como seria o possível ataque aos portos brasileiros

17 A diplomacia alemã arquivou mais de 17 reportagens de diferentes jornais com esta notícia. 
(assunto descrito em quase três páginas), as operações brasileiras, e mais dois temas descritos em poucas linhas. ${ }^{18} \mathrm{O}$ outro documento é de $15 \mathrm{de}$ junho,o qual trata de uma audiência entre Hitler e os chefes da OKW, Gen. Jodl, Vizeadmiral Krancke, Kpt. z. S. von Puttkamer sobre a ação pretendida no Brasil. Neste momento, discutiram a ação e propuseram que a mesma acontecesse em agosto, mediante aprovação de Hitler. A situação política teria que ser novamente analisada e, então, se daria a autorização definitiva. ${ }^{19}$ Ao final, nada ficou definido. No início de junho, diversos militares se envolveram nesse debate, gerando documentos. Isto é, envolveu diversas pessoas que estavam incomodadas com a ação do governo brasileiro e que desejavam diminuir o fornecimento de matérias-primas para os Estados Unidos.

Neste mesmo período, o Ministério das Relações Exteriores da Alemanha fez diversas indagações aos governos chilenos e argentinos sobre como estes perceberiam esta operação e constatou que não seria bem aceita pelos governos mencionados. Estes foram os documentos que trataram de um possível ataque aos portos brasileiros, não existindo mais documentos sobre este assunto nos arquivos militar e diplomáticos. Entretanto, é importante refletir que, para a Alemanha, o Brasil era um dos maiores fornecedores de matéria-prima para os Estados Unidos, tendo a maior frota mercante latino-americana. Todo este contexto pode ter fomentado entre os militares alemães o desejo de uma ação de retaliação. Por outro lado, o historiador precisa ter o cuidado para observar os diversos contextos que envolvem determinada ação, pois ao abordar e analisar o planejamento do ataque ao litoral brasileiro, é necessário observar que existem ações e reações. Um fato histórico, como o deste planejamento, não ocorreu de forma isolada, mas faz parte de uma sequência de fatos e ações de ambos os lados.

\section{Quadro V - Navios brasileiros atacados em julho de 1942}

\begin{tabular}{|c|c|c|c|c|}
\hline $\begin{array}{c}\text { Sequência de } \\
\text { afundamentos }\end{array}$ & $\begin{array}{l}\text { Data do } \\
\text { ataque }\end{array}$ & $\begin{array}{l}\text { Nome do navio } \\
\text { atingido }\end{array}$ & $\begin{array}{l}\text { Submarino que } \\
\text { atacou }\end{array}$ & BRT \\
\hline 10. & $26 / 07 / 1942$ & Tamandaré & U-66 & 4.942 \\
\hline
\end{tabular}

\footnotetext{
${ }^{18}$ Documento de 30 de maio de 1942, OKM - Skl, intitulado Vortragsnotiz, arquivado dentro do departamento Rechtsangelegenheiten, pasta Neutralitätsrecht - Ausübung der Neutralität: Brasilien 1939-1942, com código de arquivamento: RM/7 - 1298 do BA MA.

19 Página 300 da encadernação, 1.Skl. Ib 11/62 gKdos Chef, de 17 de junho de 1942, intitulado Vortrag, arquivado pelo SeeKriegsleitung dentro do Grundlagende und strategische Angelegenheiten - Besprechungspunkte für Lagevorträge des Ob. D. M. beim Führen (02.1942 a 12.1942), com código de arquivamento: RM/7 - 1599 do BA MA.
} 


\begin{tabular}{|l|c|c|c|c|}
\hline 11. & $28 / 07 / 1942$ & Barbacena & U-66 & 4.772 \\
\hline 12. & $28 / 07 / 1942$ & Piave & U-155 & 2.347 \\
\hline
\end{tabular}

A partir de maio, os ataques dos submarinos alemães aos navios brasileiros foram ocorrendo cada vez mais ao sul. As embarcações Paranaíba (1 de maio), Alegrete (1 de junho), Tamandaré (26 de julho), Barbacena (28 de julho) e Piave (28 de julho) foram atacados próximos ao litoral da Venezuela.

Nos registros da marinha alemã, entre fevereiro e julho de 1942 (Quadro III, IV e V), consta que o afundamento dos 13 navios mercantes brasileiros tiveram como motivação algum dos fatores a seguir: os navios não tinham sido identificados antes do ataque; havia sido liberado o ataque a todos os navios sul-americanos armados; porque tiveram atitude suspeita; tinham escolta de outros navios. Em outras palavras, internamente, as ações dos submarinos alemães eram justificadas, entretanto, perante o governo brasileiro, pela documentação alemã, nunca foi apresentada uma justificativa. Nos jornais brasileiros da época estes ataques foram considerados ações de guerra. Nesse sentido, tanto a Alemanha quanto o Brasil tomaram atitudes-beligerantes, enquanto, formalmente, haviam apenas cortado as relações diplomáticas.

Quadro VI - Navios brasileiros atacados em agosto de 1942

\begin{tabular}{|c|c|c|c|c|c|}
\hline $\begin{array}{c}\text { Sequência de } \\
\text { afundamentos }\end{array}$ & $\begin{array}{c}\text { Data do } \\
\text { ataque }\end{array}$ & $\begin{array}{c}\text { Nome do } \\
\text { navio }\end{array}$ & Mortos & $\begin{array}{c}\text { Submarino } \\
\text { que atacou }\end{array}$ & BRT \\
\hline 13. & $15 / 08 / 1942$ & Baependi & 270 & U-507 & 4.801 \\
\hline 14. & $16 / 08 / 1942$ & Araraquara & 131 & U-507 & 4.872 \\
\hline 15. & $16 / 08 / 1942$ & $\begin{array}{c}\text { Aníbal } \\
\text { Benevolo }\end{array}$ & 150 & U-507 & 1.905 \\
\hline 16. & $17 / 08 / 1942$ & Itagiba & 36 & U-507 & 2.169 \\
\hline 17. & $17 / 08 / 1942$ & $\begin{array}{c}\text { Araras ou } \\
\text { Avaré }\end{array}$ & 20 & U-507 & 1.075 \\
\hline 18. & $19 / 08 / 1942$ & Jacyra & $? ?$ & U-507 & 1.430 \\
\hline
\end{tabular}

Em agosto, observa-se que os ânimos estavam exaltados, de ambos os lados. O Comando de Guerra da Marinha Alemã autorizou manobras na costa brasileira, ocasionando o ataque a cinco navios de passageiros e a morte de mais de 600 pessoas pelo submarino alemão U-507. Esse ato foi a justificativa para o Brasil declarar guerra à Alemanha e à Itália.

Os países americanos, logo após os ataques do U-507, expressaram solidariedade, fato que preocupou a diplomacia alemã. Em 24 de agosto, o Ministério das Relações Exteriores da Alemanha foi informado que o Chile 
e o Peru se mostravam incomodados com a ação. ${ }^{20}$ Os militares alemães, conforme consta na documentação, aguardavam a definição da Argentina sobre esta questão. ${ }^{21} \mathrm{Na}$ última semana de agosto, o Skl - Seekriegsleitung (Comando de Guerra Marítima) observou que a declaração de guerra brasileira trouxe uma consequência desfavorável, pois agora teriam de cuidar ainda mais para não atingir navios argentinos ou chilenos que poderiam estar nos portos brasileiros ou navegando no litoral brasileiro. Conforme documentação interna do AA, estavam esperando quais seriam as reações do Chile e da Argentina. ${ }^{22}$ Em 4 de setembro, os militares alemães são informados pela diplomacia de seu país de que as reações na Argentina e no Chile foram muito intensas, além de todos os países latino-americanos terem declarado solidariedade ao Brasil. ${ }^{23}$ Observa-se que a diplomacia e os militares alemães acompanharam as reações dos países americanos e estavam desejosos de saber as reações dos países com os quais ainda mantinham algum tipo de relações, caso específico do Chile e da Argentina. Posteriormente, houve a determinação de que o U-507 deveria retirar-se do litoral brasileiro.

Oficialmente, em 24 de agosto de 1942, o Ministério das Relações Exteriores da Alemanha foi informado da declaração de guerra brasileira pela diplomacia portuguesa. ${ }^{24}$ Neste momento, estava encerrada qualquer expectativa de melhorar as relações entre Alemanha e Brasil. Agora as atividades eram de dois países beligerantes. Todavia, foi neste momento que

20 Telegrama $\mathrm{n}^{\circ} 3055$, de 24 de agosto de 1942, de Buenos Aires para o AA, arquivado dentro do Büro des Staatssekretärs, na pasta Brasilien (3.1942 a 8.1943, Band 2), com o código de arquivamento: R-29549 do PAAA.

${ }^{21}$ Relatórios semanais, de 17 a 23 de agosto de 1942, p. 193, do SeeKriegsleitung (Skl) Teil B VIII, temática Völkerrecht, Politik, Propaganda, denominado Lageübersicht zu Politik, Völkerrecht und Propaganda (de janeiro a dezembro de 1942), com código de arquivamento: RM/7-113 do BA MA.

22 Relatórios semanais, de 24 a 30 de agosto de 1942, p. 196 e 197, do SeeKriegsleitung, Teil B VIII, temática Völkerrecht, Politik, Propaganda, denominado Lageübersicht zu Politik, Völkerrecht und Propaganda (de janeiro a dezembro de 1942), com código de arquivamento: RM/7-113 do BA MA.

${ }^{23}$ Relatório de 4 de setembro de 1942, p. 221, do SeeKriegsleitung (Skl), Teil B VIII, temática Völkerrecht, Politik, Propaganda, denominado Lageübersicht zu Politik, Völkerrecht und Propaganda (de janeiro a dezembro de 1942), com código de arquivamento: RM/7-113 do BA MA.

${ }^{24}$ Registro $n^{\circ}$ 60, entre o diplomata português e Erdmannsdorff, de 24 de agosto de 1942, arquivado dentro do Büro des Staatssekretärs, na pasta Brasilien (3.1942 a 8.1943, Band 2), com o código de arquivamento: R-29549 do PAAA. 
o U-507 recebeu ordens de se retirar do litoral brasileiro, não havendo mais ataques. Uma provável hipótese que justifica esta ação foi a comoção explícita nos jornais argentinos e chilenos.

\section{Considerações finais}

As relações diplomáticas, políticas e militares da Alemanha com o Brasil e vice-versa, no período de 1930 a 1942, conforme a documentação pesquisada, foram guiadas pelas circunstâncias do contexto histórico vivenciado, pois as ações da política exterior, por não estarem prédeterminadas, foram sendo estruturadas aos poucos. Por isso, uma análise desse período exige detalhamentos. Com o início da guerra na Europa, as ações diplomáticas foram subordinadas aos interesses militares, mas não foi encontrado nenhum indício de que o III Reich pensasse em conquista territorial na América. O processo de total rompimento diplomático foi lento, gradual e complexo, além de guiado pelas circunstâncias de cada momento. Em janeiro de 1942, o Brasil e a Alemanha cortaram relações diplomáticas, em função de acordos realizados entre os países americanos. O período entre fevereiro e agosto de 1942, nas relações entre Alemanha e Brasil, foi caracterizado por um conjunto de ações e reações de ambos os lados; que determinaram o encerramento, em agosto, quando ficou explícito o total rompimento de quaisquer relações entre os regimes vigentes nos dois países, sem nenhuma possibilidade de reatamento, pois a guerra fora declarada.

Recebido em novembro de 2015. 